\title{
Evolution of the "fourth stage" of epidemiologic transition in people aged 80 years and over: population-based cohort study using electronic health records
}

Nisha C. Hazra ${ }^{* *}$ and Martin Gulliford ${ }^{1,2}$

\begin{abstract}
Background: In the "fourth stage" of epidemiological transition, the distribution of non-communicable diseases is expected to shift to more advanced ages, but age-specific changes beyond 80 years of age have not been reported.

Methods: This study aimed to evaluate demographic and health transitions in a population aged 80 years and over in the United Kingdom from 1990 to 2014, using primary care electronic health records. Epidemiological analysis of chronic morbidities and age-related impairments included a cohort of 299,495 participants, with stratified sampling by five-year age group up to 100 years and over. Cause-specific proportional hazards models were used to estimate hazard ratios for incidence rates over time.

Results: Between 1990 and 2014, nonagenarians and centenarians increased as a proportion of the over-80 population, as did the male-to-female ratio among individuals aged 80 to 95 years. A lower risk of coronary heart disease (HR 0.54, 95\% confidence interval [Cl]: 0.50-0.58), stroke $(0.83,0.76-0.90)$ and chronic obstructive pulmonary disease $(0.59,0.54-0$. 64) was observed among 80-84 year-olds in 2010-2014 compared to 1995-1999. By contrast, the risk of type II diabetes (2.18, 1.96-2.42), cancer (1.52, 1.43-1.61), dementia (2.94, 2.70-3.21), cognitive impairment (5.57, 5.01-6.20), and musculoskeletal pain $(1.26,1.21-1.32)$ was greater in 2010-2014 compared to 1995-1999.

Conclusions: Redistribution of the over-80 population to older ages, and declining age-specific incidence of cardiovascular and respiratory diseases in over-80s, are consistent with the "fourth stage" of epidemiologic transition, but increases in diabetes, cancer, and age-related impairment show new emerging epidemiological patterns in the senior elderly.
\end{abstract}

Keywords: Epidemiological transition, Incidence, Very old, Senior elderly, Chronic disease, Morbidity, Epidemiology, Primary care, UK

\section{Background}

The epidemiologic transition theory, proposed by Omran in 1971 [1], was developed from the demographic transition model [2] adding a more detailed consideration to causes of mortality [3]. The theory accounts for changes in ageand cause-specific mortality associated with development, generally characterized by a decline in mortality from infectious diseases and reproductive conditions, accompanied by

\footnotetext{
* Correspondence: nisha.hazra@kcl.ac.uk

'Department of Primary Care and Public Health Sciences, King's College London, 3rd Floor Addison House, Guy's Campus, London SE1 1UL, UK Full list of author information is available at the end of the article
}

the emergence of chronic non-communicable diseases as the most important causes of death [4]. Empirical studies from the United Kingdom [5-7] and other countries [3, 8] have supported the general outline of Omran's theory, but have also identified some shortcomings. In middle- and low-income countries, the emergence of HIV-related mortality and the impact of war and civil conflict show that changes in mortality are not always consistent with the direction of theory [9]. In high-income countries, the epidemiologic transition theory as originally proposed did not account for the decline in non-communicable diseases that began to be observed soon after its publication. Olshansky 
and Ault [10] proposed a "fourth stage" of epidemiologic transition, "The Age of Delayed Degenerative Diseases," in which declining age-specific mortality results in a gradual shift of non-communicable burden to older ages, with underlying causes of death showing little change overall. However, Modig et al. reported that case fatality following myocardial infarction (MI) has fallen steadily in Sweden in every year of age up to 100 since the mid-1990s [11]. This "fourth stage" of transition is associated with population aging and has assumed great importance as the senior elderly population, aged 80 years and older, has increased.

The epidemiologic transition theory is primarily concerned with changing patterns in mortality [12]. Morbidity, the incidence of diseases and health conditions, have generally been omitted from direct consideration, despite disease incidence being an important driving factor responsible for key outcomes described in the theory. There is a gap in our understanding with respect to age-specific changes in morbidity above the age of 80 years, with most studies analyzing all elderly together as a single group. The World Health Organization's recent 2015 report on Ageing and Health [13] highlights the importance of characterizing aging processes as a crucial element of the health agenda. The present study therefore analyzes electronic health records (EHRs) from a large primary care database in the UK to describe demographic and epidemiological changes in a population of senior elderly aged 80 years and older between 1990 and 2014. EHRs have been identified as a valuable resource for research into the population effect of changing demography on the epidemiology of chronic illnesses [14]. Analyses specifically aimed to describe changes in the age and sex distribution of the senior elderly population and to relate these to changes in the incidence of chronic diseases and agerelated impairments, as drivers of changes in mortality. The results are discussed in terms of the insight these provide into the progress of the "fourth stage" of epidemiologic transition in the UK.

\section{Methods}

\section{Data source}

Data were obtained from the Clinical Practice Research Datalink (CPRD), a nationally representative database of EHRs in the UK containing anonymized patient records for approximately $7 \%$ of the UK population [15-17]. The CPRD population has been shown to be representative of the UK population with respect to age, gender, and geographical distribution $[15,18]$. Data collection occurs daily as a part of normal clinical care of patients registered with participating practices [15]. The frequency of data collection is determined by patient need and patients are included in the dataset from first contact until last contact with the practice. This population-based cohort study was approved through a protocol submitted to the Medicines and Healthcare Products Regulatory Agency (MHRA) Independent Scientific Advisory Committee (ISAC) for CPRD studies (Protocol No. 15_047).

\section{Demographic data and analysis}

Demographic data were obtained from the March 2015 release of CPRD, including a complete listing of the start and end dates of CPRD records, year of birth, and date of death for all participants contributing data to CPRD. The proportion of senior elderly in the total CPRD population was determined based on individuals reaching the age of 80 years or greater, by sex and five-year period from 1990 to 2014, using mid-year counts. For each five-year period, the proportion of senior elderly in each five-year age-group, per 1,000 population, was estimated including changes over time in the past two decades and 95\% confidence intervals calculated using the Poisson distribution. Mid-year counts were calculated by including individuals reaching the age of 80 years or greater, with an active record on 30 June during the year of interest. These were aggregated for individuals 80 years or over as the numerator, with mid-year counts for all ages as denominator. Sex ratios, as the number of men per 100 women, were estimated in each year for the populations aged $\geq 80, \geq 85, \geq 90, \geq 95$, and $\geq 100$ years. Moving averages were used for the age groups $\geq 95$ and $\geq 100$ years in order to smooth the trend line due to smaller numbers. The age at death for individuals who died at the age of 80 years or over was plotted by year of death.

\section{Epidemiological data and analysis}

For epidemiological analysis, a stratified random sample was selected from the list of all patients registered at CPRD general practices. The list of eligible participants was first divided into those who had reached their 80th, 85th, 90th, 95th, and 100th birthdays while registered with CPRD during the study period, 1st January 1990 to 31st December 2014. A random sample of up to a maximum of 50,000 men and 50,000 women was taken from each stratum, resulting in 299,495 participants $(168,782$ females and 130,713 males) aged 80 years and over, including 10,560 reaching 100 years or older.

Case definitions were developed for the outcomes of coronary heart disease (CHD) [19], stroke [20], type II diabetes mellitus (DM) [21], chronic obstructive pulmonary disease (COPD), and cancer (malignant neoplasms). Age-related impairments included dementia, cognitive and memory impairment, musculoskeletal (MSK) pain, falls, factures, and hearing impairment and visual impairment, as reported previously [22]. We estimated incidence rates for the onset of a new chronic condition or age-related impairment (Additional file 1), and used a cause-specific proportional hazards models to estimate hazard ratios [23, 24], reflecting changes over time. We acknowledge the 
potential importance of competing risks for future studies that might report on cumulative incidence of specific outcomes. Models were estimated separately for each fiveyear age-group including: 80-84 years, 85-89 years, 9094 years, $95-99$ years, and $100+$ years. We contrasted two decades, divided into four five-year periods: 1995-1999, 2000-2004, 2005-2009, and 2010-2014. The years 19901994 were omitted in order to focus analysis on the most recent two decades. Multiple records were analyzed, based on successive age-groups and time periods for each participant. Hazard ratios (HRs) were adjusted for time and sex, and estimated in each age-group comparing each period to 1995-1999 as the reference period. The proportional hazards assumption was evaluated through estimation of Schoenfeld residuals. Analyses were conducted using Stata version 14.0.

\section{Results}

The total CPRD registered population increased, following the recruitment of family practices, from 1.16 million in 1990-1994 to 4.77 million in $2005-2009$ before declining to 4.45 million in 2010-2014 (Table 1). The number of individuals aged 80 years and older in CPRD increased from 53,008 (36,533 women, 16,475 men) in $1990-1994$ to 226,479 (141,359 women, 85,119 men) in 2010-2014. The proportion of the total population aged $\geq 80$ years increased from 45.7 per 1,000 (95\% confidence interval [CI]: $45.3-46.1)$ in $1990-1994$ to 50.9 per 1,000 (95\% CI: 50.7-51.1) in 2010-2014; for women the increase was from 61.0 per 1,000 (95\% CI: 61.2-62.5) to 63.0 per 1000 (95\% CI: 62.7-63.3), and in men the increase was greater, from 28.9 per 1,000 (95\% CI: $28.5-$ 29.4 ) to 38.6 per 1,000 (95\% CI: $38.4-38.9$ ). While the proportion of men $\geq 80$ years showed a consistent increase in successive periods, the proportion of women $\geq 80$ years declined by 0.5 per 1,000 from $2005-2009$ to 2010-2014 (Table 1).
As expected, each successive five-year age-group over 80 years represented a decreasing proportion of the total senior elderly population (Table 2). However, the oldest age groups generally showed the largest relative increases over time. The proportion of women aged 80-84 years decreased from $36.5 \%$ of the total over- 80 population to 29.0\% between 1990-1994 and 2010-2014. Men aged 9094 years and women aged 100 years and older were the fastest growing groups, as proportions of all over-80s. Sex difference in the numbers of senior elderly has declined over the past two decades (Fig. 1); the ratio of men per 100 women aged 80 years and older increased over the study period from 44.5 men per 100 women in 1990 to 62.7 men per 100 women in 2014. In the 85-and-over agegroup, the sex gap narrowed from 35.1 men per 100 women to 52.2 per 100 , and in the 90 -and-over age-group from 28.1 to 40.9 men per 100 women. A lesser change over time is observed for the group aged 95 years or greater. Since 1990, mean age at death among the senior elderly increased by two years; from 87 years to 89 years in women, and from 85 to 87 years in men (Fig. 2).

Changes over time in the risk of new chronic conditions are presented in Table 3, with the total number of events (Additional file 1) and overall incidence rates by age-group presented in Fig. 3. The relative hazard for CHD declined over time; at 80-84 years, CHD incidence was $46 \%$ lower (HR 0.54, 95\% CI: $0.50-0.58$ ) in 2010-2014 compared to 1995-1999 (Table 3). This decline was consistently observed in each age-group, with the exception of centenarians presenting a higher relative hazard for CHD in the most recent five-year period. This increased relative hazard might suggest a cohort effect but the data were not consistent, with a lower relative hazard being observed in earlier years. This may be a result of smaller numbers in this oldest age-group given the multiple comparisons being undertaken. The relative hazard for stroke at 90-94 years was $41 \%$ lower (HR 0.59, 95\% CI: 0.54-0.65) in 2010-2014 compared to baseline. A decrease in stroke over time was

Table 1 Proportion of CPRD population aged 80 years or older by five-year period and sex

\begin{tabular}{|c|c|c|c|c|c|c|c|c|c|}
\hline \multirow[t]{2}{*}{ Period } & \multicolumn{2}{|c|}{ Total population } & \multirow{2}{*}{$\begin{array}{l}80+\text { years per thousand } \\
\text { total population } \\
(95 \% \mathrm{Cl})\end{array}$} & \multicolumn{2}{|c|}{ Female population } & \multirow{2}{*}{$\begin{array}{l}80+\text { years per thousand } \\
\text { total population } \\
(95 \% \mathrm{Cl})\end{array}$} & \multicolumn{2}{|c|}{ Male population } & \multirow{2}{*}{$\begin{array}{l}80+\text { years per thousand } \\
\text { total population } \\
(95 \% \mathrm{Cl})\end{array}$} \\
\hline & $\begin{array}{l}80+ \\
\text { years }\end{array}$ & $\begin{array}{l}\text { All ages } \\
\text { (millions) }\end{array}$ & & $\begin{array}{l}80+ \\
\text { years }\end{array}$ & $\begin{array}{l}\text { All ages } \\
\text { (millions) }\end{array}$ & & $\begin{array}{l}80+ \\
\text { years }\end{array}$ & $\begin{array}{l}\text { All ages } \\
\text { (millions) }\end{array}$ & \\
\hline $\begin{array}{l}1990- \\
1994\end{array}$ & 53,008 & 1.16 & 45.7 (45.3 to 46.1$)$ & 36,533 & 0.59 & 61.0 (61.2 to 62.5$)$ & 16,475 & 0.57 & 28.9 (28.5 to 29.4$)$ \\
\hline $\begin{array}{l}1995- \\
1999\end{array}$ & 96,266 & 2.06 & 46.7 (46.4 to 47.0$)$ & 65,649 & 1.04 & 62.9 (62.4 to 63.4) & 30,617 & 1.02 & 30.1 (29.8 to 30.4 ) \\
\hline $\begin{array}{l}2000- \\
2004\end{array}$ & 195,829 & 4.03 & 48.5 (48.3 to 48.8$)$ & 130,126 & 2.03 & 64.0 (63.7 to 64.4$)$ & 65,703 & 2.00 & 32.8 (32.6 to 33.1 ) \\
\hline $\begin{array}{l}2005- \\
2009\end{array}$ & 235,745 & 4.77 & 49.4 (49.2 to 49.6$)$ & 152,266 & 2.40 & 63.5 (63.2 to 63.8) & 83.479 & 2.37 & 35.2 (35.0 to 35.4 ) \\
\hline $\begin{array}{l}2010- \\
2014\end{array}$ & 226,479 & 4.45 & $50.9(50.7$ to 51.1$)$ & 141,359 & 2.24 & 63.0 (62.7 to 63.3) & 85,119 & 2.20 & 38.6 (38.4 to 38.9 ) \\
\hline
\end{tabular}

Figures are means of annual mid-year counts for each period, except where indicated

$\mathrm{Cl}$, confidence interval; CPRD, Clinical Practice Research Datalink 
Table 2 Proportion of the population aged 80 years and over by age-group and sex

\begin{tabular}{|c|c|c|c|c|c|c|c|c|c|c|c|}
\hline & \multicolumn{2}{|c|}{$80-84$ years } & \multicolumn{2}{|c|}{$85-89$} & \multicolumn{2}{|c|}{$90-94$} & \multicolumn{2}{|c|}{$95-99$} & \multicolumn{2}{|c|}{$100+$} & $\begin{array}{l}\text { Total men \& } \\
\text { women } 80+\end{array}$ \\
\hline \multicolumn{12}{|l|}{ MEN } \\
\hline 1990-1994 & 51,820 & $(19.6)$ & 22,429 & $(8.5)$ & 6,502 & $(2.5)$ & 1,317 & $(0.50)$ & 309 & $(0.12)$ & 265,042 \\
\hline 1995-1999 & 89,043 & $(18.5)$ & 46,168 & (9.6) & 14,270 & (3.0) & 3,150 & $(0.65)$ & 452 & $(0.09)$ & 481,328 \\
\hline $2000-2004$ & 198,396 & (20.3) & 89,394 & (9.1) & 32,699 & (3.3) & 6,642 & $(0.68)$ & 1,385 & $(0.14)$ & 979,146 \\
\hline $2005-2009$ & 241,232 & $(20.5)$ & 126,346 & $(10.7)$ & 39,629 & (3.4) & 8,693 & $(0.74)$ & 1,497 & $(0.13)$ & $1,178,725$ \\
\hline 2010-2014 & 236,290 & $(20.9)$ & 129,861 & $(11.5)$ & 48,552 & $(4.3)$ & 9,176 & $(0.81)$ & 1,717 & $(0.15)$ & $1,132,393$ \\
\hline Change relative to $1990-1994$ & & $+6.7 \%$ & & $+35.5 \%$ & & $+74.8 \%$ & & +63.1 & & +30.1 & \\
\hline \multicolumn{12}{|l|}{ WOMEN } \\
\hline 1990-1994 & 96,683 & (36.5) & 56,824 & $(21.4)$ & 22,761 & (8.6) & 5,313 & $(2.0)$ & 1,084 & $(0.41)$ & 265,042 \\
\hline 1995-1999 & 159,566 & $(33.2)$ & 107,675 & (22.4) & 46,473 & $(9.7)$ & 12,545 & (2.6) & 1,986 & $(0.41)$ & 481,328 \\
\hline $2000-2004$ & 328,522 & $(33.6)$ & 193,143 & $(19.7)$ & 97,149 & (9.9) & 26,792 & $(2.7)$ & 5,024 & $(0.51)$ & 979,146 \\
\hline 2005-2009 & 364,524 & $(30.9)$ & 248,815 & $(21.1)$ & 107,778 & (9.1) & 33,685 & $(2.9)$ & 6,526 & $(0.55)$ & $1,178,725$ \\
\hline $2010-2014$ & 328,498 & $(29.0)$ & 225,332 & $(19.9)$ & 115,227 & $(10.2)$ & 31,016 & $(2.7)$ & 6,724 & $(0.59)$ & $1,132,393$ \\
\hline Change relative to $1990-1994$ & & $-20.5 \%$ & & $-7.2 \%$ & & $+18.5 \%$ & & $+36.6 \%$ & & $+45.2 \%$ & \\
\hline
\end{tabular}

Figures are sum of mid-year counts (\% of total population aged 80 years and over)

observed in all five-year age-groups over 80 years. The relative hazard for COPD was 76\% lower (HR 0.24, 95\% CI: 0.18-0.30) in 2010-14 among those aged 95-99 years. By contrast, relative hazards for cancer and diabetes increased over the study period. In 2010-2014, cancer risk was 38\% higher for 90-94 year olds and 69\% higher for centenarians compared to 1995-1999. All age groups showed a similar successive risk increase for cancer with each five-year period. Diabetes risk increased by $118 \%$ for 80-84 year olds, and $451 \%$ for $85-89$ year olds over the study period, but there were no new reported cases of diabetes over the age of 90 years.

Incidence of age-related impairments has generally increased over time (Table 4) across all age-groups. New diagnoses of dementia increased by almost two-fold since 1995-1999 among individuals aged 80-84 years (HR 2.94, 95\% CI: 2.70-3.21), while newly recorded cognitive impairment and memory problems were 4-5 times higher in 2010-2014 compared to 1995-1999 among those aged 80-84 years (HR 5.57, 95\% CI: 5.01-6.20), 90-94 years

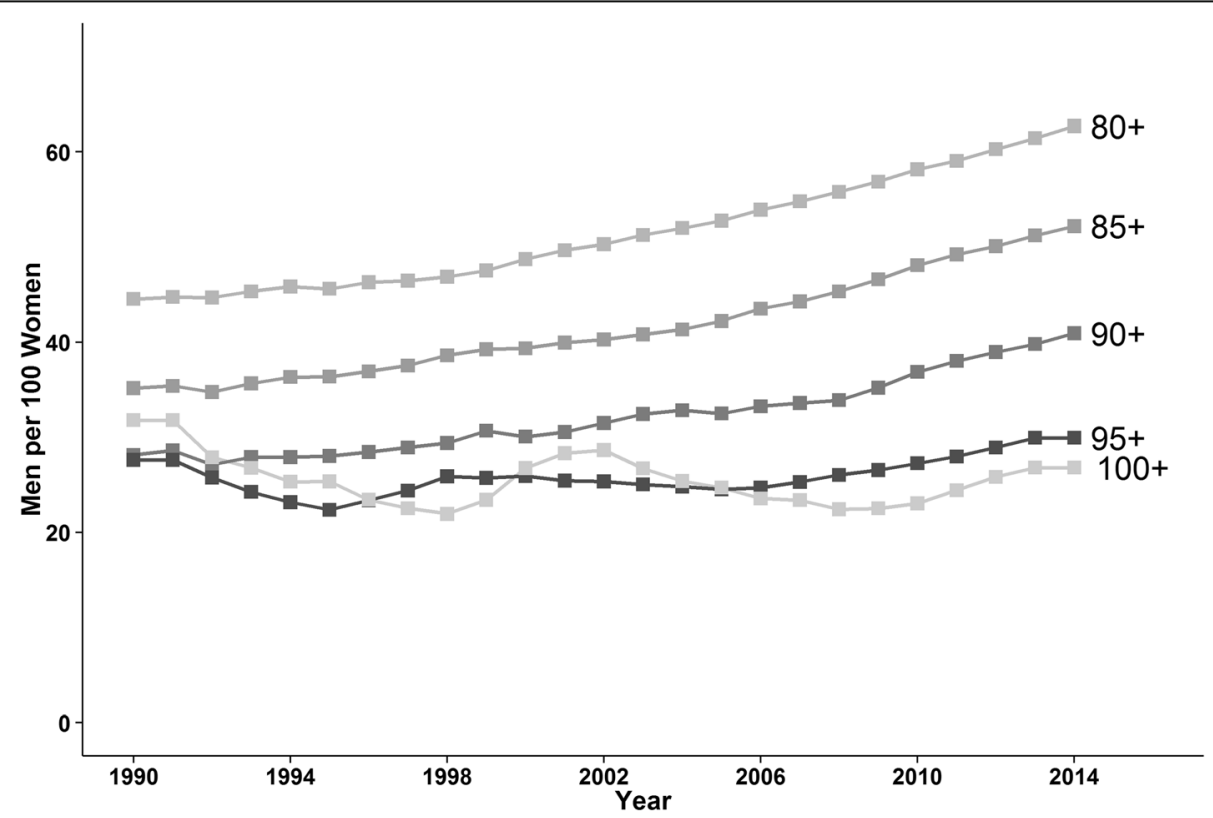

Fig. 1 Sex ratios of the number of men per 100 women between 1990 and 2014 


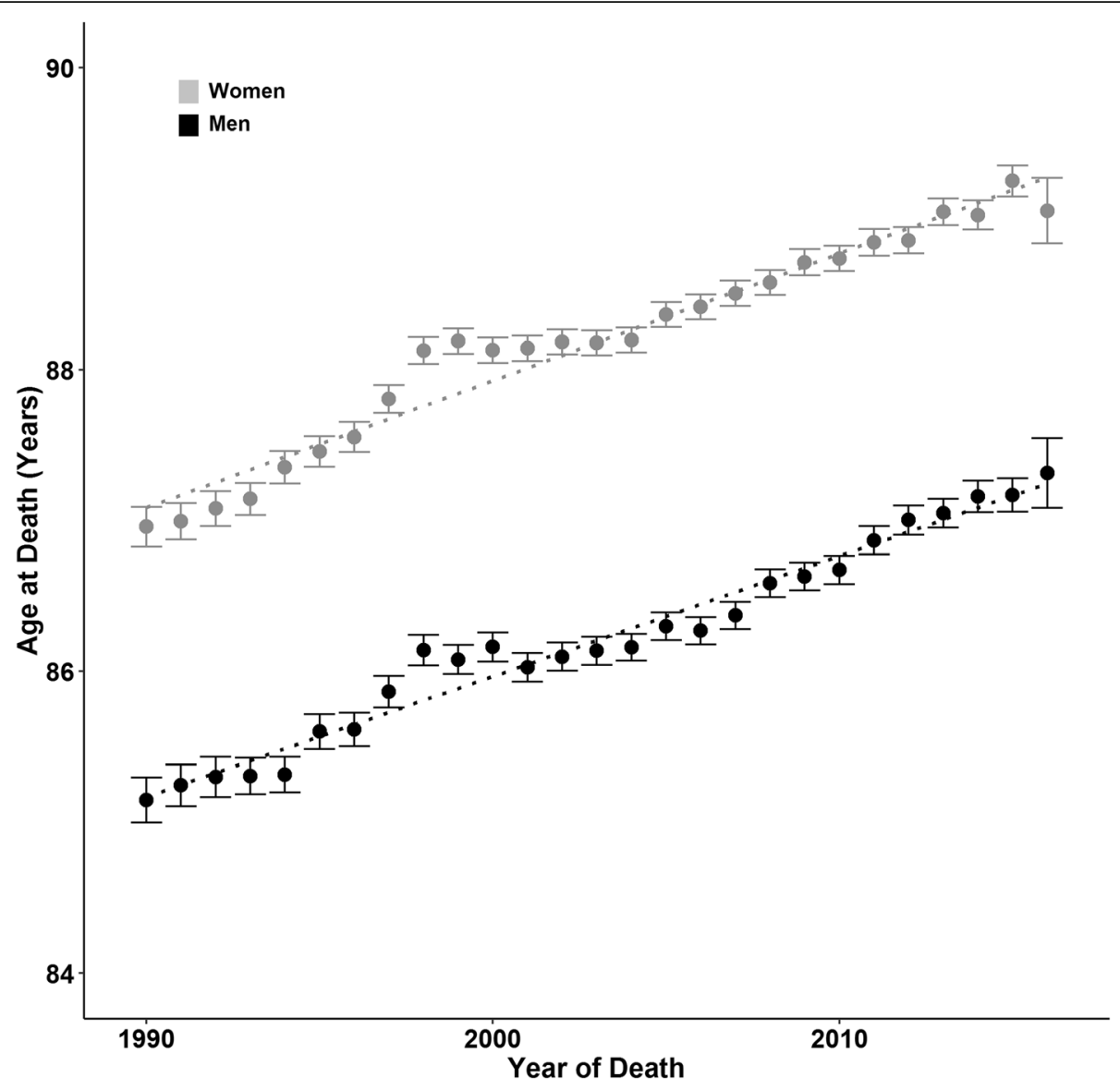

Fig. 2 Mean age at death for senior elderly by year of death. Legend: Grey, Women; Black, Men; Bars are 95\% confidence intervals

(HR 6.30, 95\% CI: 5.40-7.34) and 95-99 years (HR 6.62, 95\% CI: 4.89-8.95). MSK pain, hearing impairment, falls, and fractures increased by approximately $30-40 \%$ in 80 84 year olds, with larger increases in older age-groups. Risk of falls and fractures among centenarians increased by $50 \%$ (HR 1.50, 95\% CI: 1.12-2.02) and 57\% (HR 1.57, 95\% CI: 1.09-2.27), respectively. Figure 3 illustrates incidence rates across the whole study period by age-group. Incidence of the majority of impairments increased with age, declining beyond 95 years and in centenarians. In contrast, the majority of chronic conditions declined with age, except for stroke which increased from 80 to 95 years, and presented lower rates among centenarians.

\section{Discussion}

Our data illustrate that the population aged 80 years and older is growing rapidly, with the most rapid growth, in relative terms, being among men aged 90 to 94 years and women aged 100 years or greater. The sex gap in numbers of senior elderly is reducing while the mean age at death is increasing. Our study also presents new morbidity estimates for cause-specific hazards in the senior elderly, which are among the first age-stratified estimates reported for men and women aged 80 to 100 years or greater. These results offer support to the proposed shift in mortality from non-communicable diseases to advanced ages, consistent with the "fourth stage" of epidemiologic transition or "The Age of Delayed Degenerative Diseases." However, this empirical data also indicate that new and important epidemiological patterns are emerging in the senior elderly. While age-specific incidence for cardiovascular and respiratory diseases is declining, rates of diabetes and cancer are increasing substantially. In addition, a range of age-related impairments are increasingly occurring and rising in importance at the oldest ages, including dementia, cognitive impairment, and falls. This is consistent with the emergence of "frailty," characterized by the accumulation of functional deficits [25], as a key epidemiologic finding in the latest stage of epidemiologic transition.

\section{Comparison with existing literature}

While the decline in cardiovascular diseases (CVDs) is well-described, evidence for the extremes of age is sparse, but some studies have suggested declining incidence and mortality from CHD in adults aged more than 
Table 3 Age-specific changes in incidence of selected chronic conditions, 1995 to 2014

\begin{tabular}{|c|c|c|c|c|c|}
\hline \multirow[t]{2}{*}{ Condition } & \multirow{2}{*}{$\begin{array}{l}\text { Age } \\
\text { group } \\
\text { (years) }\end{array}$} & \multicolumn{4}{|c|}{ Hazard ratio ${ }^{a}(95 \%$ Cl) } \\
\hline & & 1995-1999 & $2000-2004$ & 2005-2009 & 2010-2014 \\
\hline \multirow[t]{5}{*}{$\overline{C H D}$} & $80-84$ & Ref. & 0.93 (0.88 to 0.98$)$ & 0.63 (0.59 to 0.67$)$ & 0.54 (0.50 to 0.58 ) \\
\hline & $85-89$ & Ref. & 0.88 (0.82 to 0.94$)$ & 0.62 (0.58 to 0.66$)$ & 0.55 (0.51 to 0.60$)$ \\
\hline & $90-94$ & Ref. & 0.90 (0.82 to 0.99$)$ & 0.67 (0.61 to 0.74 ) & 0.59 (0.67 to 0.76$)$ \\
\hline & $95-99$ & Ref. & 0.92 (0.78 to 1.10$)$ & 0.67 (0.56 to 0.79 ) & 0.70 (0.59 to 0.84 ) \\
\hline & $100+$ & Ref. & 0.78 (0.46 to 1.33 ) & 0.56 (0.32 to 0.96$)$ & 1.96 (1.17 to 3.30$)$ \\
\hline \multirow[t]{5}{*}{ Stroke } & $80-84$ & Ref. & 0.95 (0.88 to 1.02 ) & 0.80 (0.74 to 0.87 ) & 0.83 (0.76 to 0.90 ) \\
\hline & $85-89$ & Ref. & 0.83 (0.77 to 0.89 ) & 0.68 (0.63 to 0.73 ) & 0.71 (0.66 to 0.77 ) \\
\hline & $90-94$ & Ref. & 0.78 (0.71 to 0.84$)$ & 0.63 (0.58 to 0.69 ) & 0.59 (0.54 to 0.65 ) \\
\hline & $95-99$ & Ref. & 0.79 (0.69 to 0.91$)$ & 0.56 (0.48 to 0.64$)$ & 0.53 (0.46 to 0.62 ) \\
\hline & $100+$ & Ref. & 0.58 (0.40 to 0.85$)$ & 0.51 (0.35 to 0.74 ) & 0.44 (0.30 to 0.65 ) \\
\hline \multirow[t]{5}{*}{ COPD } & $80-84$ & Ref. & 0.66 (0.62 to 0.71$)$ & 0.63 (0.59 to 0.68 ) & 0.59 (0.54 to 0.64 ) \\
\hline & $85-89$ & Ref. & 0.57 (0.52 to 0.62$)$ & 0.52 (0.48 to 0.56$)$ & 0.47 (0.43 to 0.52 ) \\
\hline & $90-94$ & Ref. & 0.47 (0.42 to 0.53$)$ & 0.35 (0.31 to 0.40$)$ & 0.36 (0.32 to 0.41$)$ \\
\hline & $95-99$ & Ref. & 0.40 (0.32 to 0.51$)$ & 0.28 (0.22 to 0.35$)$ & 0.24 (0.18 to 0.30$)$ \\
\hline & $100+$ & Ref. & 0.44 (0.23 to 0.86$)$ & 0.31 (0.16 to 0.62 ) & 0.15 (0.07 to 0.35 ) \\
\hline \multirow[t]{5}{*}{ Cancer } & $80-84$ & Ref. & 1.08 (1.02 to 1.15$)$ & 1.31 (1.24 to 1.39 ) & 1.52 (1.43 to 1.61$)$ \\
\hline & $85-89$ & Ref. & 1.07 (1.00 to 1.14$)$ & 1.36 (1.28 to 1.45$)$ & 1.45 (1.36 to 1.54$)$ \\
\hline & $90-94$ & Ref. & 1.15 (1.05 to 1.26$)$ & 1.33 (1.22 to 1.45$)$ & 1.38 (1.26 to 1.50$)$ \\
\hline & $95-99$ & Ref. & $1.08(0.91$ to 1.28$)$ & $1.20(1.02$ to 1.42$)$ & 1.44 (1.22 to 1.70$)$ \\
\hline & $100+$ & Ref. & 0.87 (0.46 to 1.63 ) & 1.17 (0.65 to 2.12) & 1.69 (0.95 to 3.00 ) \\
\hline \multirow[t]{2}{*}{ Diabetes mellitus ${ }^{b}$} & $80-84$ & Ref. & 1.62 (1.46 to 1.78$)$ & 2.02 (1.83 to 2.23 ) & 2.18 (1.96 to 2.42 ) \\
\hline & $85-89$ & Ref. & 2.45 (2.01 to 2.99$)$ & 3.65 (3.02 to 4.41$)$ & 5.41 (4.47 to 6.53 ) \\
\hline
\end{tabular}

Cl confidence interval

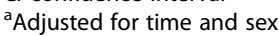

${ }^{\mathrm{b}} \mathrm{No}$ incident diabetes events over 90 years of age

75 years [26, 27]. There is also evidence of a decline in CVD risk in Sweden, including both MI and stroke, for the period between 1994 to 2010 observed beyond 85 years, with the rate of improvement plateauing with age [11]. This is consistent with our findings for CHD, but not for stroke. Stroke incidence in the UK is reported to have declined by $42 \%$ between 1999 and 2008 in individuals aged 80 years or greater [28]. We similarly found declines in stroke incidence over time, but also report these decreases among the senior elderly becoming larger in magnitude with each increasing age-group up to $100+$ years; a $17 \%$ decline (HR 0.83 , 95\% CI: $0.76-$ 0.90 ) in incidence at $80-84$ years and a $56 \%$ decline (HR 0.44, 95\% CI: 0.30-0.65) in centenarians between 1995-1999 and 2010-2014. Declining trends in classic cardiovascular risk factors in recent years, including reductions in smoking, high blood pressure, and cholesterol levels [29-31], may be contributing to the observed reductions in cardiovascular and respiratory diseases in our study. The use of anti-hypertensive medications has also increased over the past two decades [31], consistent with our observed declines in CHD and other reports on reductions in CHD risk [32] and CHD mortality [26]. In contrast, recent research in the UK report mortality rising in many places among pensioners over 85 , possibly linked to increasing austerity measures [33], which may be explained by a shift in morbidity and mortality away from CVD and towards other types of fatal chronic conditions and impairments. Changes in COPD incidence rates over time have not been reported in the UK elderly and reports from the United States give conflicting results [34, 35]. Among adults in the UK, a peak in age-sex standardized COPD incidence was reported in 2004, suggesting we may have reached a possible summit of COPD incidence and prevalence in England overall [36], however we report consistent declines in COPD incidence since 1995-1999 in all age-groups of senior elderly. Diabetes prevalence has increased worldwide [37], as has the age-adjusted incidence of diabetes in the US [38] and the distribution of obesity as a key risk factor for diabetes [39, 40]. Our findings reveal that increases in diabetes risk extend to all age-groups of senior elderly beyond 80 years of age. 


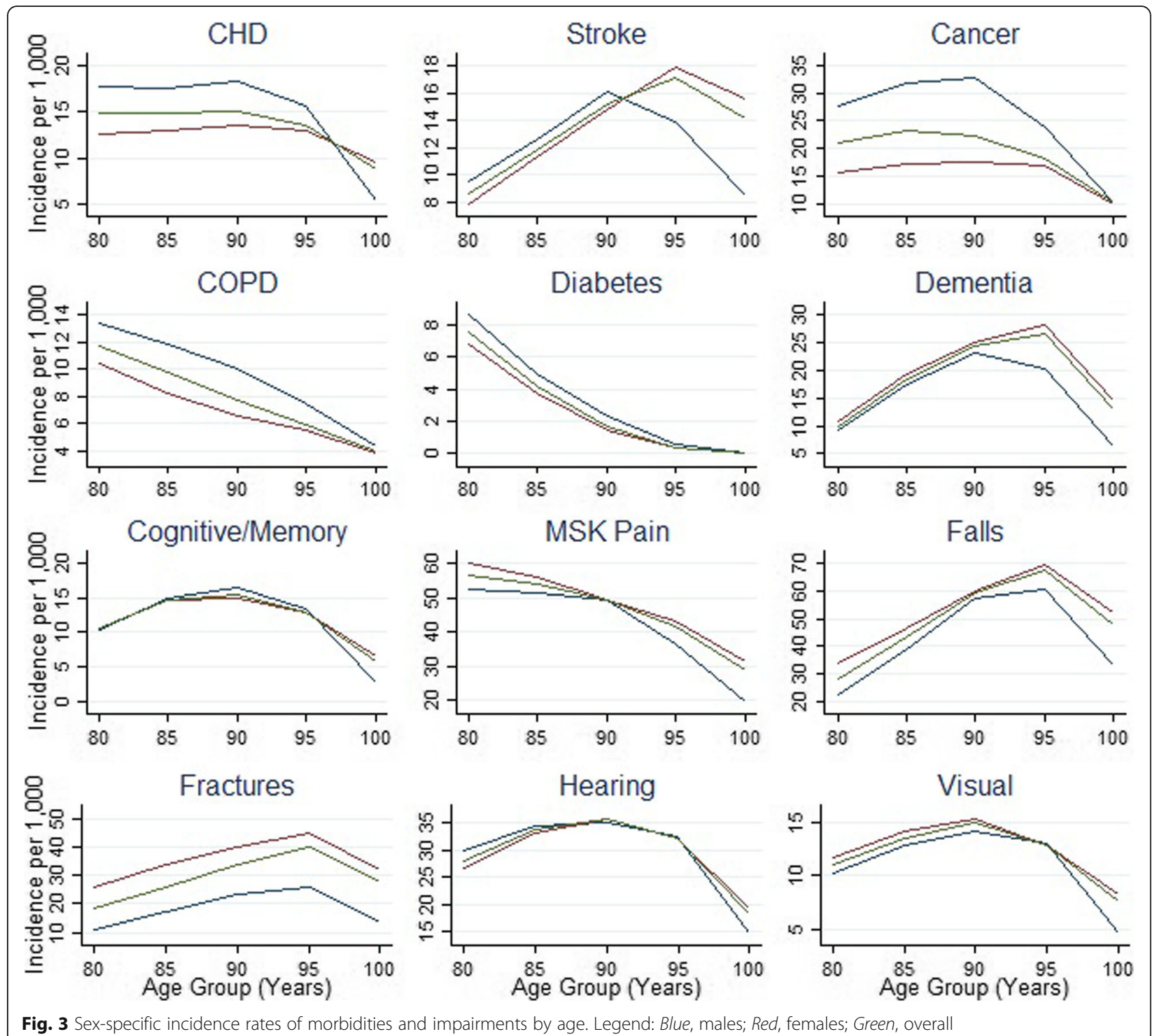

Increasing risk of cancer in all age-groups of our cohort is supported by reports from Cancer Research UK for individuals aged 75 and over [41], as well as increasing adiposity indicators and obesity [30] reported for the UK in recent decades.

The occurrence of new age-related impairments in our cohort, particularly degenerative mental health conditions, have risen steadily since the mid-90s. The reasons for this change remain poorly understood, but may be resulting from increased longevity associated with lower risk of cardiovascular mortality [35]. Age-specific dementia prevalence in the UK among over- $65 \mathrm{~s}$ was previously reported to have fallen between 1989 and 2008 [42], contrasting to our findings showing an increasing frequency of new dementia and cognitive impairment diagnoses in over-80s over the past two decades. These opposing trends may be indicative of a shift in dementia towards more extreme ages, with falling prevalence in younger elderly and increasing incidence in the senior elderly. Our observed increases in the risk of hearing impairment may be explained by better diagnosis in primary care over time or improved access to treatment resulting in increased recording of diagnostic codes in CPRD. It is also possible that there have been improvements in the delivery of care, which could explain the observed declines in visual impairment among over-80s as a result of improvements in diabetic retinopathy screening and increased rates of cataract extractions. At older age groups, the incidence of falls and fractures presented large increases over time, with larger increases in fractures compared to falls. Increasing polypharmacy in older age, with a greater likelihood of drug interactions 
Table 4 Age-specific changes in incidence of selected age-related impairments over the age of 80 years, 1995 to 2014

\begin{tabular}{|c|c|c|c|c|c|}
\hline \multirow[t]{2}{*}{ Condition } & \multirow{2}{*}{$\begin{array}{l}\text { Age } \\
\text { group } \\
\text { (years) }\end{array}$} & \multicolumn{4}{|c|}{ Hazard ratio ${ }^{a}(95 \% \mathrm{Cl})$} \\
\hline & & 1995-1999 & $2000-2004$ & 2005-2009 & 2010-2014 \\
\hline \multirow[t]{5}{*}{ Dementia } & $80-84$ & Ref. & 1.28 (1.17 to 1.39$)$ & 1.85 (1.70 to 2.01$)$ & 2.94 (2.70 to 3.21$)$ \\
\hline & $85-89$ & Ref. & 1.21 (1.12 to 1.30$)$ & 1.55 (1.44 to 1.66$)$ & 2.40 (2.23 to 2.57$)$ \\
\hline & $90-94$ & Ref. & $1.16(1.06$ to 1.26$)$ & 1.50 (1.37 to 1.63$)$ & 2.03 (1.87 to 2.20 ) \\
\hline & $95-99$ & Ref. & $1.32(1.12$ to 1.55$)$ & 1.76 (1.51 to 2.04$)$ & 2.43 (2.09 to 2.82 ) \\
\hline & $100+$ & Ref. & 1.30 (0.70 to 2.42$)$ & 2.18 (1.21 to 3.90$)$ & 2.52 (1.41 to 4.50$)$ \\
\hline \multirow[t]{5}{*}{ Cognitive/memory } & $80-84$ & Ref. & 2.29 (2.05 to 2.55$)$ & 3.61 (3.25 to 4.01$)$ & 5.57 (5.01 to 6.20$)$ \\
\hline & $85-89$ & Ref. & 2.36 (2.11 to 2.63 ) & 3.84 (3.46 to 4.27$)$ & 5.64 (5.08 to 6.27 ) \\
\hline & $90-94$ & Ref. & 2.53 (2.16 to 2.98 ) & 4.25 (3.64 to 4.96$)$ & 6.30 (5.40 to 7.34$)$ \\
\hline & $95-99$ & Ref. & 2.49 (1.81 to 3.42 ) & 4.31 (3.17 to 5.84 ) & 6.62 (4.89 to 8.95 ) \\
\hline & $100+$ & Ref. & 2.28 (0.67 to 7.77$)$ & $3.96(1.22$ to 12.8$)$ & 6.02 (1.88 to 19.3 ) \\
\hline \multirow[t]{5}{*}{ MSK pain } & $80-84$ & Ref. & 1.06 (1.02 to 1.10$)$ & $1.30(1.25$ to 1.35$)$ & 1.26 (1.21 to 1.32$)$ \\
\hline & $85-89$ & Ref. & 1.06 (1.01 to 1.11$)$ & 1.29 (1.23 to 1.35$)$ & 1.22 (1.16 to 1.28$)$ \\
\hline & $90-94$ & Ref. & 1.00 (0.93 to 1.06$)$ & 1.25 (1.17 to 1.33$)$ & 1.18 (1.11 to 1.26$)$ \\
\hline & $95-99$ & Ref. & 1.00 (0.88 to 1.14$)$ & 1.33 (1.18 to 1.50$)$ & 1.32 (1.16 to 1.49$)$ \\
\hline & $100+$ & Ref. & 0.83 (0.55 to 1.25$)$ & 1.45 (1.00 to 2.10$)$ & 1.63 (1.12 to 2.37 ) \\
\hline \multirow[t]{5}{*}{ Falls } & $80-84$ & Ref. & 1.08 (1.03 to 1.13$)$ & 1.18 (1.13 to 1.24$)$ & 1.26 (1.19 to 1.32$)$ \\
\hline & $85-89$ & Ref. & 1.05 (1.00 to 1.10$)$ & 1.11 (1.06 to 1.16$)$ & 1.18 (1.13 to 1.23 ) \\
\hline & $90-94$ & Ref. & 0.96 (0.91 to 1.02$)$ & 1.11 (1.05 to 1.17$)$ & 1.13 (1.07 to 1.19 ) \\
\hline & $95-99$ & Ref. & 1.03 (0.94 to 1.14$)$ & 1.21 (1.11 to 1.33$)$ & 1.25 (1.14 to 1.37$)$ \\
\hline & $100+$ & Ref. & 1.10 (0.81 to 1.49$)$ & 1.33 (0.99 to 1.79$)$ & 1.50 (1.12 to 2.02 ) \\
\hline \multirow[t]{5}{*}{ Fractures } & $80-84$ & Ref. & 0.94 (0.89 to 1.00$)$ & 1.18 (1.12 to 1.26$)$ & 1.38 (1.30 to 1.47$)$ \\
\hline & $85-89$ & Ref. & 0.96 (0.91 to 1.02$)$ & 1.20 (1.13 to 1.27$)$ & 1.49 (1.41 to 1.58$)$ \\
\hline & $90-94$ & Ref. & 0.97 (0.90 to 1.05$)$ & 1.19 (1.11 to 1.28$)$ & 1.42 (1.32 to 1.53$)$ \\
\hline & $95-99$ & Ref. & 1.11 (0.97 to 1.27$)$ & 1.41 (1.24 to 1.60$)$ & 1.61 (1.42 to 1.83 ) \\
\hline & $100+$ & Ref. & 0.95 (0.64 to 1.41$)$ & 1.32 (0.91 to 1.92) & 1.57 (1.09 to 2.27 ) \\
\hline \multirow[t]{5}{*}{ Hearing impairment } & $80-84$ & Ref. & 1.14 (1.08 to 1.19$)$ & 1.26 (1.20 to 1.32$)$ & 1.28 (1.22 to 1.35$)$ \\
\hline & $85-89$ & Ref. & 1.21 (1.15 to 1.28$)$ & $1.34(1.27$ to 1.41$)$ & 1.32 (1.25 to 1.39 ) \\
\hline & $90-94$ & Ref. & 1.22 (1.13 to 1.32$)$ & $1.40(1.30$ to 1.51$)$ & 1.43 (1.32 to 1.54$)$ \\
\hline & $95-99$ & Ref. & 1.40 (1.20 to 1.62$)$ & 1.65 (1.43 to 1.91$)$ & 1.81 (1.56 to 2.10$)$ \\
\hline & $100+$ & Ref. & 0.85 (0.51 to 1.41$)$ & 1.41 (0.88 to 2.25) & 1.75 (1.10 to 2.78$)$ \\
\hline \multirow[t]{5}{*}{ Visual impairment } & $80-84$ & Ref. & 0.77 (0.72 to 0.82 ) & 0.62 (0.58 to 0.66$)$ & 0.50 (0.46 to 0.54$)$ \\
\hline & $85-89$ & Ref. & 0.85 (0.80 to 0.91$)$ & 0.69 (0.65 to 0.74$)$ & 0.54 (0.50 to 0.59 ) \\
\hline & $90-94$ & Ref. & 0.92 (0.84 to 1.01$)$ & 0.86 (0.79 to 0.95$)$ & 0.67 (0.61 to 0.74 ) \\
\hline & $95-99$ & Ref. & 1.03 (0.85 to 1.25$)$ & 1.00 (0.83 to 1.20$)$ & 0.88 (0.73 to 1.07 ) \\
\hline & $100+$ & Ref. & 0.76 (0.44 to 1.31$)$ & $0.74(0.44$ to 1.25$)$ & 0.51 (0.29 to 0.90$)$ \\
\hline
\end{tabular}

Cl confidence interval

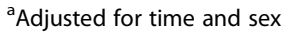

or inappropriate prescribing may sometimes contribute to iatrogenic risks such as falls [31, 43, 44]. This increase may also be attributed to increasing numbers of older people living alone in the UK and not making appropriate adaptations to their homes, as recently reported by the International Longevity Centre (ILC-UK) [45]. Recent increases in age-related impairments in our cohort reveal an important emerging characteristic of the current stage of epidemiologic transition.

\section{Strengths and limitations}

This study has the strengths of a large nationally representative data resource, enabling us to analyze longitudinal demographic data for up to $7 \%$ of the UK 
population. Use of primary care EHRs facilitated analysis of longitudinal and age-specific estimates for a wide range of chronic morbidities and age-related impairments in a large sample. Approximately $98 \%$ of the UK population will be registered with primary care [46], ensuring our results are population-based. We acknowledge that misclassification of birth year may occur, especially for people born longer ago, due to poor recording practices at time of birth or if birth date is reported by proxies. The analysis used clinical records for health conditions and these may be affected by misclassification including over- or underrecording, or changes in the depth and quality of coding, which may vary over time. In general, diagnoses recorded into EHRs have high predictive value [47], but we acknowledge that diagnoses may be less reliable at older ages if, for example, fewer investigations are performed. Recording of age-related conditions such as dementia may be underestimated, however our data should provide reliable figures for relative changes over time. There may also be changes over recent years in the use of particular diagnostic labels. While these reservations suggest the need for further epidemiological studies in very old people, prospective cohort studies may suffer from different limitations including biases from differential selection, participation, and attrition. These may be minimized through the use of EHRs for cohort selection and follow-up.

\section{Conclusions}

Empirical evidence reveals that the "fourth stage" of epidemiologic transition is more nuanced than originally proposed. At the oldest ages, populations exhibit important epidemiologic changes that are not yet well-characterized beyond 80 years. We recommend that, where data permits, the practice of reporting on "the elderly" as one group must change in order to more fully understand the distribution of disease and disability in different subgroups of the over- 80 population. This will be a vital component in producing better evidence to improve the health and care of the senior elderly, and to help inform a shift in thinking from "chronic disease prevention" to "healthy aging" that is important at the oldest ages. Greater acknowledgement among policymakers and clinicians of the observed growth in multi-morbidity and shift away from the presently existing single-disease framework in health care [48] will be crucial in the coming years to better manage the health care needs of an aging population. Improved public health interventions are also required to reduce levels of obesity in the middle-aged and elderly populations in order to facilitate the prevention of new diabetes and cancer diagnoses in older age. However, more evidence is also needed to inform the prevention of accumulating functional deficits and age-related impairments.

\section{Additional file}

Additional file 1: Table S1. Incidence rates of chronic morbidities by age group, 1995-2014. Table S2. Incidence rates of age-related impairments by age group, 1995-2014. Table S3. Incidence rates for chronic morbidities by ten-year period. Table S4. Incidence rates for age-related impairments by ten-year period. (DOCX $35 \mathrm{~kb}$ )

\section{Abbreviations}

UK: United Kingdom; EHR: Electronic health record; CPRD: Clinical Practice Research Datalink; MHRA: Medicines and Healthcare Products Regulatory Agency; ISAC: Independent Scientific Advisory Committee; CHD: Coronary heart disease; DM: Diabetes mellitus; COPD: Chronic obstructive pulmonary disease; MSK: Musculoskeletal; HR: Hazard ratio; US: United States

\section{Acknowledgements}

Open access for this article was funded by King's College London.

\section{Funding}

MG is supported by the NIHR Biomedical Research Centre at Guy's and St. Thomas' NHS Foundation Trust.

\section{Availablility of data and materials}

The data that support the findings of this study are available from CPRD but restrictions apply to the availability of these data, which were used under license for the current study, and so are not publicly available. Data are however available from the authors upon reasonable request and with permission of CPRD.

\section{Authors' contributions}

$\mathrm{NH}$ and $\mathrm{MG}$ designed the study. MG obtained the data and $\mathrm{NH}$ analyzed and interpreted the data, and prepared the manuscript. Both authors read and approved the final manuscript.

Competing interests

The authors declare no competing interests.

\section{Consent for publication}

All data used in this study are anonymised. This study was approved through a protocol submitted to the Medicines and Healthcare Products Regulatory Agency (MHRA) Independent Scientific Advisory Committee (ISAC) for CPRD studies (Protocol No. 15_047).

Ethics approval and consent to participate

Not applicable.

\section{Publisher's Note}

Springer Nature remains neutral with regard to jurisdictional claims in published maps and institutional affiliations.

\section{Author details}

'Department of Primary Care and Public Health Sciences, King's College London, 3rd Floor Addison House, Guy's Campus, London SE1 1UL, UK.

${ }^{2} \mathrm{NIHR}$ Biomedical Research Centre at Guy's and St Thomas' NHS Foundation Trust, Great Maze Pond, London SE1 9RT, UK.

Received: 16 November 2016 Accepted: 4 May 2017

Published online: 12 May 2017

\section{References}

1. Omran AR. The epidemiologic transition. A theory of the epidemiology of population change. Milbank Mem Fund Q. 1971;49:509-38.

2. Alexandersson $\mathrm{G}$. The demographic transition: model and reality. Fennia. 1981;159:35-42.

3. Mackenbach JP. The epidemiologic transition theory. J Epidemiol Community Health. 1994:48:329-31.

4. Santosa A, Wall S, Fottrell E, Hogberg U, Byass P. The development and experience of epidemiological transition theory over four decades: a systematic review. Glob Health Action. 2014;7:23574. 
5. Carson C, Hajat S, Armstrong B, Wilkinson P. Declining vulnerability to temperature-related mortality in London over the 20th century. Am J Epidemiol. 2006;164:77-84.

6. Wild SH, Fischbacher C, Brock A, Griffiths C, Bhopal R. Mortality from all causes and circulatory disease by country of birth in England and Wales 2001-2003. J Public Health (Oxf). 2007:29:191-8.

7. Weden MM, Brown RA. Historical and life course timing of the male mortality disadvantage in Europe: epidemiologic transitions, evolution, and behavior. Soc Biol. 2006:53:61-80

8. Gulliford MC. Epidemiological transition in Trinidad and Tobago, west indies 1953 to 1992. Int J Epidemiol. 1996;25:357-65.

9. Kuate Defo B. Demographic, epidemiological, and health transitions: are they relevant to population health patterns in Africa? Glob Health Action. 2014;2014:7.

10. Olshansky SJ, Ault AB. The fourth stage of the epidemiologic transition: the age of delayed degenerative diseases. Milbank Q. 1986;64:355-91.

11. Modig K, Andersson T, Drefahl S, Ahlbom A. Age-specific trends in morbidity, mortality and case-fatality from cardiovascular disease. Myocardial infarction and stroke in advanced Age: evaluation in the Swedish population. PLoS One. 2013;8:e64928

12. Omran AR. The epidemiologic transition: a theory of the epidemiology of population change. Milbank Q. 2005;83:731-57.

13. World Health Organization. World Report on Ageing and Health. Geneva: WHO Press; 2015.

14. Wellcome Trust. Frontiers Meeting on the Use of Electronic Patient Records for Research and Health Benefit. 2016: 2007. http://docplayer.net/1818277Frontiers-meeting-use-of-electronic.html.

15. Herrett E, Gallagher AM, Bhaskaran K, Forbes H, Mathur R, van Staa T, Smeeth L. Data resource profile: clinical practice research datalink (CPRD). Int J Epidemiol. 2015;44:827-36.

16. Williams T, van Staa T, Puri S, Eaton S. Recent advances in the utility and use of the general practice research database as an example of a UK primary care data resource. Ther Adv Drug Safety. 2012;3:89-99.

17. Mathur R, Bhaskaran K, Chaturvedi N, Leon DA, van Staa T, Grundy E, Smeeth L. Completeness and usability of ethnicity data in UK-based primary care and hospital databases. J Public Health (Oxf). 2014;36:684-92.

18. Quint JK, Millett ERC, Joshi M, Navaratnam V, Thomas SL, Hurst JR, Smeeth L, Brown JS. Changes in the incidence, prevalence and mortality of bronchiectasis in the UK from 2004-2013: a population based cohort study. Eur Respir J. 2016; 47:186-93.

19. Bhattarai N, Charlton J, Rudisill C, Gulliford MC. Coding, recording and incidence of different forms of coronary heart disease in primary care. PLoS One. 2012;7:e29776.

20. Gulliford MCJ, Ashworth M, Rudd AG, Toschke AM, for the eCRT Research Team. Selection of medical diagnostic codes for analysis of electronic patient records. Application to stroke in a primary care database. PLoS One. 2009:4(9):1-10. e7168.

21. Hamada S, Gulliford MC. Mortality in type 2 diabetes at 80 years or older in relation to $\mathrm{HbA} 1 \mathrm{c}$, blood pressure, and total cholesterol. J Am Geriatr Soc. 2016;64(7):1425-31.

22. Hazra NC, Dregan A, Jackson S, Gulliford MC. Differences in health at Age 100 according to Sex: population-based cohort study of centenarians using electronic health records. J Am Geriatr Soc. 2015:63:1331-7.

23. Noordzij M, Leffondré K, van Stralen KJ, Zoccali C, Dekker FW, Jager KJ. When do we need competing risks methods for survival analysis in nephrology? Nephrol Dial Transplant. 2013;28(11):2670-7.

24. Austin PC, Lee DS, Fine JP. Introduction to the analysis of survival data in the presence of competing risks. Circulation. 2016;133:601.

25. Rockwood K, Andrew M, Mitnitski A. A comparison of two approaches to measuring frailty in elderly people. J Gerontol A Biol Sci Med Sci. 2007;62: 738-43.

26. Bajekal M, Scholes S, Love H, Hawkins N, O'Flaherty M, Raine R, Capewell S. Analysing recent socioeconomic trends in coronary heart disease mortality in England, 2000-2007: a population modelling study. PLoS Med. 2012;9: e1001237.

27. Bajekal M, Scholes S, O'Flaherty M, Raine R, Norman P, Capewell S. Unequal trends in coronary heart disease mortality by socioeconomic circumstances, England 1982-2006: an analytical study. PLoS One. 2013;8:e59608.

28. Lee S, Shafe ACE, Cowie MR. UK stroke incidence, mortality and cardiovascular risk management 1999-2008: time-trend analysis from the General Practice Research Database. BMJ Open. 2011;1(2):e000269.
29. Kuulasmaa K, Tunstall-Pedoe H, Dobson A, Fortmann S, Sans S, Tolonen H, Evans A, Ferrario M, Tuomilehto J. Estimation of contribution of changes in classic risk factors to trends in coronary-event rates across the WHO MONICA Project populations. Lancet. 2000;355:675-87.

30. Alageel $\mathrm{S}$, Wright AJ, Gulliford MC. Changes in cardiovascular disease risk and behavioural risk factors before the introduction of a health check programme in England. Prev Med. 2016;91:158-63.

31. Dregan A, Ravindrarajah R, Hazra N, Hamada S, Jackson SH, Gulliford MC Longitudinal trends in hypertension management and mortality among octogenarians: prospective cohort study. Hypertension. 2016;68:97-105.

32. Falaschetti E, Mindell J, Knott C, Poulter N. Hypertension management in England: a serial cross-sectional study from 1994 to 2011. Lancet. 2014;383: 1912-9.

33. Loopstra R, McKee M, Katikireddi SV, Taylor-Robinson D, Barr B, Stuckler D. Austerity and old-age mortality in England: a longitudinal cross-local area analysis, 2007-2013. J R Soc Med. 2016;109:109-16.

34. American Lung Association. Trends in COPD (Chronic Bronchitis and Emphysema): Morbidity and Mortality. Epidemiology and Statistics Unit, Research and Health Education Division. 2013.

35. Akushevich I, Kravchenko J, Ukraintseva S, Arbeev K, Yashin Al. Time trends of incidence of age-associated diseases in the US elderly population: Medicare-based analysis. Age Ageing. 2013;42:494-500.

36. Simpson CR, Hippisley-Cox J, Sheikh A. Trends in the epidemiology of chronic obstructive pulmonary disease in England: a national study of 51804 patients. Br J Gen Pract. 2010;60:e277-84.

37. NCD Risk Factor Collaboration (NCD-RisC). Worldwide trends in diabetes since 1980: a pooled analysis of 751 population-based studies with 4.4 million participants. Lancet. 2016;387:1513-30.

38. Centers for Disease Control and Prevention: Crude and Age-Adjusted Rates of Diagnosed Diabetes per 100 Civilian, Non-Institutionalized Population, United States, 1980-2014. 2015.

39. NCD Risk Factor Collaboration (NCD-RisC). Trends in adult body-mass index in 200 countries from 1975 to 2014: a pooled analysis of 1698 populationbased measurement studies with 19.2 million participants. Lancet. 2016;387: 1377-96.

40. Abraham TM, Pencina KM, Pencina MJ, Fox CS. Trends in diabetes incidence: the Framingham heart study. Diabetes Care. 2015;38:482-7.

41. Cancer Incidence by age. 2016. [http://www.cancerresearchuk.org/healthprofessional/cancer-statistics/incidence/age\#heading-Four] Accessed 5 Sept 2016.

42. Wu Y-T, Fratiglioni L, Matthews FE, Lobo A, Breteler MMB, Skoog I, Brayne C. Dementia in western Europe: epidemiological evidence and implications for policy making. Lancet Neurol. 2015;15(1):116-24.

43. Hazra NC, Dregan A, Jackson S, Gulliford MC. Drug utilization and inappropriate prescribing in centenarians. J Am Geriatr Soc. 2016;64:1079-84.

44. Campese V, Schneider EL. Reevaluating the use of antihypertensive medications, a first step toward reducing polypharmacy in very old patients. J Clin Hypertens (Greenwich). 2010;12:621-4.

45. International Longevity Centre (ILC-UK). The state of the nation's housing. 2016. http://www.ilcuk.org.uk/index.php/publications/publication_details/ the_state_of_the_nations_housing_an_ilc_uk_factpack.

46. Health and Social Care Information Centre. Attribution Data Set GPRegistered Populations Scaled to ONS Population Estimates - 2011. Published Feb 2, 2012. http://content.digital.nhs.uk/pubs/gpregpop11.

47. Herrett EL, Thomas SL, Smeeth L. Validity of diagnoses in the general practice research database. Br J Gen Pract. 2011;61:438-9.

48. Barnett K, Mercer SW, Norbury M, Watt G, Wyke S, Guthrie B. Epidemiology of multimorbidity and implications for health care, research, and medical education: a cross-sectional study. Lancet. 2012;380(9836):37-43. 